\title{
Detecção de Escherichia coli e Salmonella spp. em microbiota intestinal de Psittaciformes em fase de reabilitação para soltura
}

\author{
Detection of Escherichia coli and Salmonella spp. in the intestinal microbiot of Psittacifomes \\ in rehabilitation process for wildlife reintroduction
}

\author{
Guilherme Augusto MARIETTO-GONÇALVES'; Sílvia Maria de ALMEIDA²; Edna Tereza de LIMA³; \\ Raphael Lucio ANDREATTI FILHO ${ }^{4}$ \\ ${ }^{1}$ Laboratório de Ornitopatologia da Faculdade de Medicina Veterinária da Universidade Estadual Paulista - Botucatu-SP \\ ${ }^{2}$ Instituto Floravida, Botucatu-SP \\ ${ }^{3}$ Curso de Medicina Veterinária da Universidade Federal do Paraná, Palotina-PR \\ ${ }^{4}$ Departamento de Clínica Veterinária da Faculdade de Medicina Veterinária da Universidade Estadual Paulista - Botucatu-SP
}

\begin{abstract}
Resumo
A Escherichia coli é uma bactéria pertencente à família Enterobacteriacea que faz parte da microbiota entérica de mamíferos e de muitas espécies de aves. A Salmonella spp. também pertence à mesma família, sendo responsável por surtos de infecção alimentar em humanos e frequentemente isoladas de aves domésticas e aves silvestres. O presente estudo analisou a frequência de ambas as bactérias em Psittaciformes em processo de reabilitação para a vida livre. De 89 aves analisadas $19 \%$ estavam infectadas com E. coli e 1,12\% com Salmonella spp. Realizou-se uma análise do perfil de resistência a antibióticos onde se observou a eficiência de estreptomicina, tetraciclina, trimetoprim e gentamicina sobre as amostras. As amostras de E. coli foram submetidas ao teste de Vermelho-Congo e ao teste Atividade Hemolítica, onde se observaram $70,6 \%$ de amostras positivas para o primeiro e $53 \%$ para o segundo teste.
\end{abstract}

Palavras-chave: Escherichia coli. Salmonella. Ornitopatologia. Saúde animal. Psittaciformes

\begin{abstract}
Escherichia coli is a bacteria of the Enterobacteriacea family and it is part of the enterical microflora of mammals and of many species of birds. Salmonella spp. also belongs to the family Enterobacteriacea, it is responsible for human feed toxinfection outbreaks and usually isolated from domestic and wild birds. The present study analyzed the frequency of both agents in Psittaciformes in rehabilitation process for wildlife reintroduction. In 89 birds analyzed, $19 \%$ were infected with E. coli and 1,12\% with Salmonella spp. It was carried out an analysis of the profile of antibiotic resistance in which was observed the efficiency of estreptomicin, tetraciclin, trimetoprim and gentamicin over the samples. The samples of E. coli were submitted to the Congo Red Binding test and to the Hemolisis test and 70,6\% of positive samples for the first test and $53 \%$ for the second one were observed.
\end{abstract}

Keywords: Escherichia coli. Salmonella. Ornithopathology. Animal health. Psittaciformes.

A microbiota intestinal de Psittaciformes é composta principalmente por bactérias Gram-positivas, destacando-se as do gênero Lactobacillus spp., $\mathrm{Ba}$ cillus spp., Corynebacterium spp., Streptomyces spp., Gaffkya spp., Aerococcus spp., Micrococcus spp., Staphylococcus spp., e Streptococcus spp., não hemolíticos além de fungos e leveduras ${ }^{1,2}$, não se considerando saudável a presença de bactérias Gram-negativas³. Em estudos observou-se que o grau de contamina- ção por E. coli em psitacídeos cativos clinicamente saudáveis variou entre 18 e $31 \%$, sendo muito frequente em cacatuas e menos frequente nas demais

Correspondência para:

Guilherme Augusto Marietto-Gonçalves

Caixa Postal: 560, CEP: 18618-000, Distrito de Rubião Júnior, Botucatu-SP,

Tel./Fax: (014) 3811-6293.

E-mail: gmarietto_ornito@fmvz.unesp.br

Recebido: 28/03/2007

Aprovado: 04/03/2010 
espécies ${ }^{2,4}$, sendo que Nakamura et al. $^{5}$ observaram multirresistência a antibióticos em 75,1\% de amostras isoladas em psitacídeos. A existência de um número muito baixo de informações sobre a patogenicidade da E. coli em psitacídeos evidencia a necessidade do desenvolvimento de estudos ${ }^{4}$.

O presente trabalho teve como objetivos a análise da presença de E. coli e Salmonella spp. em fezes dos Psittaciformes em fase de reabilitação para a vida livre no Projeto Centrofauna - Instituto Floravida, BotucatuSP, Brasil, oriundos de apreensão de tráfico animal da Polícia Ambiental do Estado de São Paulo da região de Botucatu-SP; a determinação do perfil de susceptibilidade antimicrobiana das amostras e a verificação da presença de fator de invasão e da produção de hemolisina das amostras de E. coli isoladas.

O estudo foi realizado no período de março de 2006 a março de 2007 e as amostras foram coletadas por via de suabe cloacal mediante contenção física das aves no Instituto Floravida/Botucatu-SP. Após a coleta, os suabes eram depositados em tubos de ensaio individuais contendo $10 \mathrm{~mL}$ de água peptonada estéril, mantidos sob refrigeração a $5{ }^{\circ} \mathrm{C}$ e encaminhados ao Laboratório de Ornitopatologia do Hospital Veterinário da Faculdade de Medicina Veterinária e Zootecnia da Universidade Estadual Paulista, Campus Botucatu-SP (LO/HV/ FMVZ-UNESP/Botucatu-SP) para o processamento e interpretação das análises. Ao chegar no LO/HV/ FMVZ-UNESP/Botucatu-SP, as amostras foram incubadas por 24 horas em estufa bacteriológica a $37^{\circ} \mathrm{C}$; em seguida repassou-se $1 \mathrm{~mL}$ de cada amostra de água peptonada para os Caldos seletivos Tetrationato e SelenitoCistina, que foram novamente incubadas por 24 horas. Após este período, as amostras foram plaqueadas em ágar MacConkey e ágar Hektoen e reincubadas por mais 24 horas. Em sequência ao último período de incubação, realizou-se a leitura de crescimento bacteriano e após a constatação da presença de colônias características de $E$. coli ou Salmonella spp. realizou-se triagem bioquímica com os meios ágar TSI (Tríplice-Açúcar-Ferro), SIM,
Caldo Malonato e Ureia. As amostras que se apresentaram compatíveis nestes testes foram submetidas à bateria bioquímica completa para confirmação da presença de E. coli e Salmonella spp. ${ }^{6}$.

As amostras isoladas foram desafiadas aos seguintes antibióticos para se avaliar a sensibilidade a estes: cefaclor, ciprofloxacina, enrofloxacina, estreptomicina, gentamicina, sulfonamida, tetraciclina e trimetoprima. As amostras foram cultivadas em Caldo MillerHilton, incubadas a $37^{\circ} \mathrm{C}$ por 24 horas para E. coli e $40{ }^{\circ} \mathrm{C}$ para Salmonella spp. Pipetou-se $0,1 \mathrm{~mL}$ de cada caldo (com sua respectiva amostra) em placas de Ágar Mueller-Hilton, espalhando-se a gota de forma homogênea por toda a superfície da placa com uma alça de Drigalski. Em seguida, depositaram-se os discos contendo os antibióticos utilizados no estudo. Por fim, incubaram-se as placas a $37^{\circ} \mathrm{C} / 40^{\circ} \mathrm{C}$ por 24 horas, realizando-se a leitura após este período ${ }^{7}$.

Para se avaliar o fator de invasão das amostras de $E$. coli isoladas foi realizado o teste de Vermelho-Congo (TVC) em ágar Vermelho-Congo ${ }^{8}$. As amostras foram cultivadas em caldo Cérebro-Coração por $37^{\circ} \mathrm{C}$ por 24 horas, semeadas no ágar Vermelho-Congo e incubadas a $37^{\circ} \mathrm{C}$ por 24 horas. Para avaliação de fator de virulência, realizou-se o teste de atividade hemolítica (TAH), semeando-se as amostras em ágar Sangue (sangue ovino desfibrinado), incubados a $37^{\circ} \mathrm{C}$ por 24 horas ${ }^{9}$. Para o TVC, utilizou-se como controle positivo uma amostra de E. coli EIEC e para o TAH uma amostra de E. coli EHEC, sendo utilizada como controle negativo para ambos os testes uma amostra de E. coli K12. Consideraram-se positivas no TVC as amostras que apresentaram colônias com coloração vermelha, e negativas, as com colônias branco-rosadas. Para o teste TAH as amostras que apresentavam halo transparente ao redor das colônias foram consideradas positivas e negativas as amostras sem formação de halo ${ }^{10}$.

Foram analisadas 89 amostras de suabe cloacal de três espécies diferentes de psitacídeos: dezesseis de Periquitão-maracanã (Aratinga leucophthalmus), um 
de Papagaio do mangue (Amazona amazonica) e setenta e dois de Papagaio-verdadeiro (A. aestiva). Em $19 \%(17 / 89)$ das amostras analisadas detectou-se a presença de Escherichia coli, sendo que 23,5\% (4/17) foram isoladas em exemplares de A. leucophthalmus e 76,5\% (13/17) em A. aestiva. Isolou-se apenas uma amostra de Salmonella spp. em A. aestiva, representando $1,12 \%(1 / 89)$ do material analisado.

No exame de antibiograma observou-se alta resistência de E. coli a sulfonamida e a cefaclor, $83 \%$ e $71 \%$ das amostras analisadas respectivamente, e alto índice de sensibilidade para estreptomicina, tetraciclina e trimetropima, ambas com $94 \%$ de inibição. Gentamicina e ciprofloxacina também apresentaram alto índice de inibição, porém com 17,6\% de amostras resistentes (Figura 1). A amostra de Salmonella spp. mostrou-se sensível à estreptomicina, tetraciclina, trimetropima e gentamicina e resistente aos demais antibióticos. Do total de amostras de E. coli constatou-se que 5,9\% (1/17) foram sensíveis a todos antibióticos testados, 29,4\% (5/17) foram sensíveis a um antibiótico, 23,5\% (4/17) a dois antibióticos e 41,2\% (7/17) apresentaram multirresistência (mais de três antibióticos), sendo a interação enrofloxacina/sulfonamida/cefaclor a mais observada. Das 17 amostras de E. coli isoladas, 70,6\% (12/17) foram positivas para o TVC e 53\% (9/17) para o TAH, sendo que do total das amostras, $29,4 \%(5 / 17)$ foram positivas para ambos os testes, apenas 5,8\% (1/17) foi negativa para ambos os testes.

$O$ isolamento de $E$. coli é relatado com frequência em psitacídeos doentes ou submetidos ao estresse de captura e transporte ${ }^{11,12}$, porém as aves analisadas neste estudo positivas para E. coli e Salmonella spp. apresentavam-se clinicamente saudáveis. A colonização intestinal por E. coli em psitacídeos pode variar em função da espécie, condições sanitárias das aves, quantidade de indivíduos no mesmo viveiro e da alimentação, ou seja, sempre com a influência das condições do cativeiro ${ }^{13,14,15,16}$. Uma vez tendo condições de se instalar nos intestinos a capacidade da E. coli poder causar doenças é dependente da presença de fatores de virulência, como fímbria, cápsula, endotoxina e hemolisinas, sendo que a presença de vários fatores confere uma patogenicidade maior $^{14,17,18}$.

O TVC é capaz de distinguir se uma cepa de E. coli é invasiva ou não, enquanto o teste de TAH avalia a capacidade de hemólise das bactérias ${ }^{10,19,20}$. No estudo

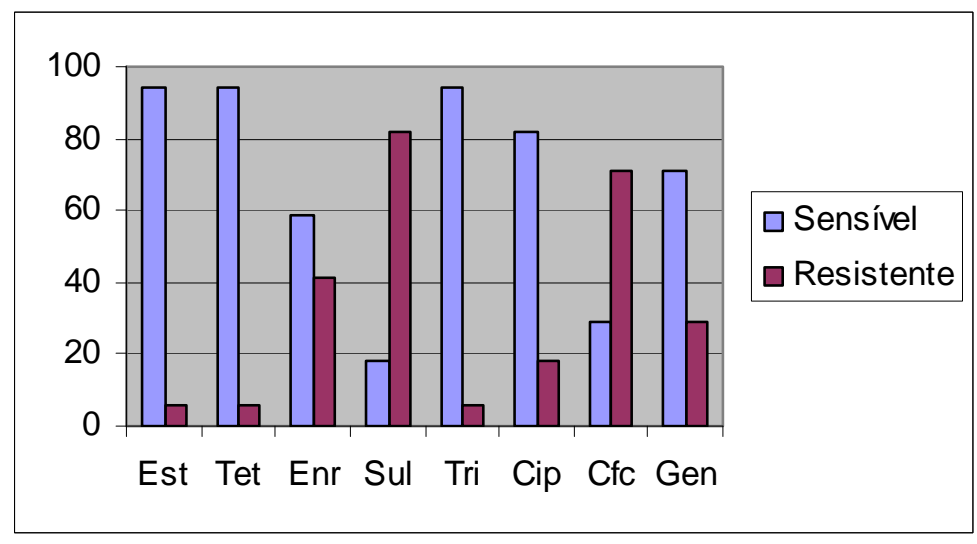

Figura 1 - Perfil de sensibilidade/resistência a antibióticos das amostras de Escherichia coli isoladas de psitacídeos cativos em processo de reabilitação pelo Laboratório de Ornitopatologia durante os anos de 2006 e 2007. Est: estreptomicina; Tet: tetraciclina; Enr: enrofloxacina; Sul: sulfonamida; Tri: trimetoprima; Cip: ciprofloxacina; Gen: gentamicina 
foi possível identificar cinco amostras positivas para ambos os testes, o que indica que possam se tratar de cepas com potencial de patogenicidade. Uma pequena porção da população de E. coli possui fatores de patogenicidade, sendo que ambas (patogênicas e apatogênicas) podem conviver harmoniosamente na mesma ave sem causar lesões ${ }^{17}$, devido ao seu caráter oportunista. O TVC é um ensaio simples e prático recomendado como um método de triagem por Sharma, Soni e Meharchandani ${ }^{21}$ e a associação com o TAH apresentou-se como ferramenta in vitro útil para o estudo inicial de patogenicidade das amostras de E. coli isoladas de psitacídeos no presente estudo. A avaliação inicial de patogenicidade com a associação de ambos os testes já foi utilizada por Roy et al. ${ }^{10} \mathrm{em}$ estudos com amostras oriundas de codorna japonesa.

Devido ao fato de bactérias Gram-negativas não fazerem parte da microbiota de psitacídeos ${ }^{16}$, como sugerido por Mattes et al. ${ }^{4}$ realizou-se antibioticoterapia das aves positivas, independente das amostras terem ou não apresentado um perfil de patogenicidade nos testes realizados. Optou-se pelo uso da tetraciclina no tratamento das duas espécies de bactérias mediante a análise do perfil de resistência realizado, sendo constatada a ausência dos agentes após a repetição da análise microbiológica. A ave portadora de Salmonella spp. foi retirada do programa de reabilitação e mantida isolada devido ao risco de disseminação, tanto no local onde se desenvolve o projeto de reabilitação de fauna como futuramente em vida livre e pela possibilidade de uma vez infectada (mesmo após tratamento) a ave se tornar portadora assintomática ${ }^{16,22,23}$.

Como observado por Styles e Flammer ${ }^{8}$ a tetraciclina, a trimetropima e a gentamicina foram os antibióticos que apresentaram boa eficiência nas amostras de E. coli isoladas de psitacídeos, diferentemente de amostras isoladas de aves industriais, em que comumente se observa resistência a estes antibióticos ${ }^{24,25}$. Ao contrário do observado por Rantala ${ }^{26}$, que relata o aumento do número de Salmonella ao utilizar tetraciclina no tratamento de salmonelose em pintos, o tratamento realizado na ave positiva para Salmonella spp. foi eficaz. Quinolonas são antibióticos recomendados para o tratamento de salmoneloses ${ }^{22}$, a amostra isolada apresentou resistência para as duas testadas (ciprofloxacina e enrofloxacina). A ineficiência do uso de enrofloxacina no tratamento de salmonelose em psitacídeos já foi reportada por Kanashiro et al. ${ }^{16}$.

Boa conduta de higiene é um ponto crítico para prevenção e controle de doenças em aves cativas, sendo que o acúmulo de material orgânico em recintos é algo inevitável. No processo de limpeza, antes do enxágue e da aplicação de desinfetantes, é importante que haja uma boa remoção física de toda matéria orgânica, e para a desinfecção, hipoclorito de sódio, amônia quartenária e fenóis são produtos comumente utilizados ${ }^{27}$. Além de boa desinfecção do ambiente, a associação de diferentes medidas que inclui boa ventilação e controle populacional de recintos, redução de estresse ambiental e de manipulação, ótima nutrição e a utilização de probióti$\cos ^{4}$ podem ajudar diretamente e indiretamente na manutenção da integridade da microbiota intestinal de psitacídeos e assim impedir a livre circulação e fixação de bactérias Gram-negativas (patogênicas ou não) na mesma.

A monitoria da presença de bactérias Gram-negativas na microbiota entérica de Psittaciformes cativos é um procedimento que deve ser incluído na rotina de criadouros particulares, parques zoológicos, hospitais veterinários e principalmente em projetos de reintrodução de aves cativas para a vida livre, primeiramente por não pertencerem a microbiota normal dessas aves e devido ao risco de disseminação de possíveis patógenos em recintos de alocação e de dispersão destes no meio ambiente, contribuindo assim na cadeia epidemiológica de várias doenças entéricas para o homem e outros animais. 


\section{Agradecimentos}

Ao Prof. Ass. Dr. Josias Rodrigues do Laboratório de Microbiologia do Departamento de Microbiologia

\section{Referências}

1.BANGERT, R. L.; CHO, B. R.; WIDDERS, P. R.; STAUBER, E. H.; WARD, A. C. A survey of aerobic bacteria and fungi in the feces of healthy psittacine birds. Avian Diseases, v. 32, n. 1, p. 46-52, 1988

2.FLAMMER, K.; DREWES, L. A. Species-related differences in the incidence of gram-negative bacteria isolated from the cloaca of clinically normal psittacine birds. Avian Diseases, v. 32, n. 32, p. 79-83, 1988.

3.TRABULSI, L. R. Microbiologia. São Paulo: Ateneu, 1996. 386 p.

4.MATTES, B. R.; CONSIGLIO, S. A. S.; ALMEIDA, B. Z.; GUIDO, M. C.; ORSI, R. B.; SILVA, R. M.; COSTA, A.; FERREIRA, A. J. P.; KNÖBL, T. Influência da biossegurança na colonização intestinal por Escherichia coli em psitacídeos. Arquivos do Instituto Biológico, v. 72, n. 2, p. 13-16, 2005.

5.NAKAMURA, M.; FUKAZAWA, M.; YOSHIMURA, H.; KOEDA, T. Drug resistance and R plasmids in Escherichia coli strains isolated from imported pet birds. Microbiology and Immunology, v. 24, n. 12, p. 1131-1138, 1980.

6.HOLT, J. G.; KRIEG, N. R.; SNEATH, P. H. A.; STALEY, J. T.; WILLIAMS, S. T. Bergey's manual of determinative bacteriology. 9. ed. Baltimore: Willians \& Wilkins, 1994. 787 p.

7.BAUER, A. W.; KIRBY, W. M.; SHERRIS, J. C.; TURK, M. Antibiotic susceptibility testing by a standardized single disc method. American Journal of Clinical Pathology, v. 45, n. 4 , p. $493-496,1966$.

8.STYLES, D. K.; FLAMMER, K. Congo Red Binding of Escherichia coli isolated from the cloacae of psittacine birds. Avian Diseases, v. 35, n. 1, p. 46-48, 1991.

9.QUINN, P. J.; CARTER, M. E.; MARKEY, B.; CARTER, G. R. Clinical veterinary microbiology. London: Wolfe, 1994. $684 \mathrm{p}$.

10.ROY, P.; PURUSHOTHAMAN, V.; KOTEESWARAN, A.; DHILLON, A. S. Isolation, characterization, and antimicrobial drug resistance pattern of Escherichia coli isolated from japanese quail and their environment. Journal of Applied Poultry Research, v. 15, p. 442-446, 2006.

11.RAPHAEL, B. L.; IVERSON, W. O. Coligranuloma and psittacosis in an Amazon parrot. Journal of the American Veterinary Medical Association, v. 177, n. 9, p. 927-929, 1980.

12.NAKAMURA, M.; FUKAZAWA, M.; YOSHIMURA, $\mathrm{H}_{\text {; }}$ KOEDA, T. Drug resistance and R plasmids in Escherichia coli strains isolated from imported pet birds. Microbiology and Immunology, v. 24, n. 12, p. 1131-1138, 1980.

13. GODOY, S. N. Psittaciformes (Arara, Pagagaio, Periquito). In: CUBAS, Z. S.; SILVA, J. C. R.; CATÃO-DIAS, J. L. (Ed.). Tratado de animais selvagens. São Paulo: Roca, 2006. p. 222-251.

14.SCHREMMER, C.; LOHR, J. E.; WASTLHUBER, U.; KÖSTERS, J.; RAVELSHOFER, K.; STEINRÜCK, H.; WIELER, L. H. Enteropathogenic Escherichia coli in psittaciformes. Avian Pathology, v. 28, n. 4, p. 349-354, 1999. e Imunologia do Instituto de Biociências da Universidade Estadual Paulista, campus Botucatu-SP por ceder gentilmente as amostras controle para o estudo.

15. GRAHAN, C. L.; GRAHAN, D. L. Occurrence of Escherichia coli in feces of psittacine birds. Avian Diseases, v. 22, n. 4, p. 717-720, 1978.

16. KANASHIRO, A. M. I.; DE CASTRO, A. G. M.; CARDOSO, A. L. S. P.; TESSARI, E. N. C.; TAVECHIO, A. T. Persistência de Salmonella spp. após antibióticoterapia em psitacídeos pertencentes a um criadouro comercial. Arquivos do Instituto Biológico, v. 69, n. 2, p. 99-101, 2002.

17.ANDREATTI FILHO, R. L. Colibacilose Aviária. In ANDREATTI FILHO, R. L. Saúde aviária e doenças. 1.ed. São Paulo: Roca, 2007. p. 112-117.

18. BARNES, H. J.; GROSS, W. B. Collibacillosis. In: CALNEK, B. W.; BARNES, H. J.; BEARD, C. W.; MCDOUGALD, L. R.; SAIF, Y. M. Diseases of poutry. 10. ed. Iowa: The Iowa State University Press, 1997. p. 131-141.

19.BERKHOFF, H. A.; VINAL, A. C. Congo red medion to distinguish between invasice and non-invasice Escherichia coli pathogenic for poultry. Avian Diseases, v. 30, n. 1, p. 117-121, 1985.

20.COSTA, M. M.; SILVA, M. S.; SPRICIGO, D. A.; WITT, N. M.; MARCHIORO, S. B.; KOLLING, L.; VARGAS, A. P. C. Caracterização epidemiológica, molecular e perfil de resistência aos antimicrobianos de Escherichia coli isoladas de criatório de suínos do sul do Brasil. Pesquisa Veterinária Brasileira, v. 26, n. 1, p. 5-8, 2006.

21.SHARMA, K. K.; SONI, S. S.; MEHARCHANDANI, S. Congo red dye agar test as an indicator test for detection of invasive bovine Escherichia coli. Veterinarski Arhiv, v. 76, n. 1, p. 363$366,2006$.

22.BERCHIERI JÚNIOR, A. Salmoneloses Aviárias. In BERCHIERI JÚNIOR, A.; MACARI, M. Doenças das aves. Campinas: FACTA, 2000. p. 185-195.

23.GAST, R. G. Salmonella Infections. In: CALNEK, B. W. BARNES, H. J.; BEARD, C. W.; MCDOUGALD, L. R.; SAIF, Y. M. Diseases of poutry. 10. ed. Iowa: The Iowa State University Press, 1997. p. 81-82.

24. AL-GHAMDI, M. S.; EL-MORSY, F.; AL-MUSTAFA, Z. H.; AL-RAMADHAN, M.; HANIF, M. Antibiotic resistence of Escherichia coli isolated from poultry workers, patient and chicken in the eastern province of Soult Arabia. Tropical Medicine and International Health, v. 4, n. 4, p. 278-283, 1999.

25.ZANATTA, G. F.; KANASHIRO, A. M. I.; CASTRO, A. G M.; CARDOSO, A. L. S. P.; TESSARI, E. N. C.; PULICI, S. C. P. Susceptibilidade de amostras de Escherichia coli de origem aviária a antimicrobianos. Arquivos do Instituto Biológico, v. 71, n. 3, p. 283-286, 2004.

26. RANTALA, M. Nitrovin and tetracycline: a comparison of their effect on salmonellosis in chicks. British Poultry Science, v. 15 , n. 3, p. 299-303, 1974.

27.CUBAS, Z. S. Special challenges of mainteining wild animals in captivity in South America. Revue Scientifique et Technique (International Office of Epizootics), v. 15, n. 1, p. 267-287, 1996. 